\title{
Modelling of Grinding in an Air Classifier Mill Based on a Fundamental Material Function ${ }^{\dagger}$
}

\author{
Lutz Vogel \\ Degussa AG, Process Technology and \\ Engineering* \\ Wolfgang Peukert \\ Institute of Particle Technology, \\ University Erlangen-Nuremberg **
}

\begin{abstract}
An approach to quantifying the impact grinding performance of different materials is presented. Based on a dimensional analysis and on fracture mechanical considerations, two material parameters, $f_{\text {Mat. }}$ and $W_{m \text {,min }}$, are derived theoretically. $f_{\text {Mat. }}$. characterises the resistance of particulate material against fracture during impact comminution. $W_{m, \text { min }}$ gives the mass-specific energy which a particle can absorb without fracture. Using this approach, various materials over a wide size range, e.g. different polymers, crystalline substances, glass and limestone, can be characterised quantitatively. The derived material parameters are applied to the systematic modelling of grinding in impact mills. A population balance model is presented and the results of the simulation for an air classifier mill are shown. The developed model permits a clear separation of the influence of material properties, mill-specific features and operating conditions, thus enabling a deeper understanding of the impact grinding process.
\end{abstract}

\section{INTRODUCTION}

Every material performs differently in the milling process and exhibits different grinding characteristics. A systematic and quantitative characterisation of the grinding performance of a powder is currently beyond scope because both the stressing of the particles in a mill and the breakage behaviour even under well-defined stressing conditions are not sufficiently understood, and the comparison of materials in a comminution process can therefore only be realised with the help of milling tests. These tests give results which are of value only for the type of mill under consideration. The possibility of transferring these results to other mills is debatable. This situation and the

\footnotetext{
* Rodenbacher Chaussee 4, 63457 Hanau, Germany

Lutz.Vogel@degussa.com

**Cauerstrasse 4, 91058 Erlangen/Germany

W.Peukert@lfg.uni-erlangen.de

${ }^{\dagger}$ Accepted: June, 2003
}

lack of understanding of the influence of material properties on the comminution process is totally unacceptable. In this paper, an approach which describes the grinding performance of different products independent of the mill properties is introduced.

Furthermore, the modelling of impact grinding processes is addressed. In order to operate a modern and flexible process, it is essential to be able to at least estimate the effect of changes to the operational parameters or products on the process result. Even with a statistically optimised experimental strategy, the required effort in time and cost for this purpose is still considerable. A systematic and physically reliable computer simulation of the process would be a fast and cheap alternative to overcome these problems. Furthermore, a realistic model can help to understand the milling process and the interaction of single process steps. An approach to the simulation of grinding in mills based on a population balance model is presented. A simple model to describe the individual process steps inside the mill (i.e. grinding, classification and transport) was chosen. The main focus was 
on areleanseparation between material and operationaluparameters, respectively, in order to investigate their influence on the comminution result separately.

\section{MATERIAL CHARACTERISATION}

\subsection{Similarity Considerations}

The breakage probability and the breakage function quantify the result of particle fracture concerning the size distribution of the milling product. The breakage probability $\mathrm{P}_{\mathrm{B}}$ describes the fraction of particles which is destroyed in an experiment. The breakage function $\mathrm{B}$ gives the size distribution of the fragments. The breakage of particles of different size, of different material and of different shape at various stressing conditions can be investigated with the help of similarity considerations. The following deduction is based on an approach first presented by Rumpf [1].

Analysing the parameters which have an influence on particle breakage leads to Eq. 1. It contains 13 parameters describing the particle stressing, the particle size and shape and bulk material properties. The single parameters of influence are combined to ten dimensionless groups, thus reducing the number of independent parameters and underlining combined influences. In Eq. 1, $\mathrm{W}_{\mathrm{V}}$ denotes the volumetric, specific stressing energy, $\mathrm{k}$ the number of stressing events and $v_{d}$ the velocity of the deformation, which together define the stressing conditions. $\mathrm{x}$ is the initial particle size and $\psi$ a shape parameter, taking the effect of different particle shapes on fracture formally into account. The bulk material properties are quantified by the following parameters: $\beta_{\max }$ denotes the crack extension energy per unit of created surface, $E^{\prime}$ the storage modulus of the particle material, $E^{\prime \prime}$ the corresponding viscous loss modulus, $\mathrm{H}$ the hardness, $v$ the Poisson ratio. $v_{\text {fract }}$ is the velocity of the crack propagation, $\mathrm{v}_{\mathrm{el}}$ the velocity of the propagation of elastic waves and $l_{i}$ the inherent initial crack length or flaw size.

$$
\mathrm{P}_{\mathrm{B}}, \mathrm{B}=\mathrm{f}\left\{\mathrm{k}, \frac{\mathrm{W}_{\mathrm{V}} \cdot \mathrm{x}}{\beta_{\max }}, \frac{\mathrm{E}^{\prime} \cdot 1_{\mathrm{i}}}{\beta_{\max }}, \frac{\mathrm{H}}{\mathrm{E}^{\prime}}, \frac{\mathrm{E}^{\prime \prime}}{\mathrm{E}^{\prime}}, \frac{\mathrm{l}_{\mathrm{i}}}{\mathrm{x}}, \frac{\mathrm{v}_{\mathrm{d}}}{\mathrm{v}_{\mathrm{el}}}, \frac{\mathrm{v}_{\text {fract }}}{\mathrm{v}_{\mathrm{el}}}, \Psi, v\right\}
$$

Eq. 1 takes a large set of relevant parameters for particle fracture in general into account. For the case of impacting particles and the conditions considered here, it can be simplified. The velocity of propagating cracks is always significantly less than the velocity of elastic waves for brittle materials [2, 3]. The crack extension can be considered as quasi-static here and the ratio $\mathrm{v}_{\text {fract }} / \mathrm{v}_{\mathrm{el}}$ will not have an influence on particle breakage. The velocity of the propagation of elastic waves is about $2400 \mathrm{~m} / \mathrm{s}$ for brittle polymers such as PMMA and PS. For glass it even reaches values of $5800 \mathrm{~m} / \mathrm{s}$ [3]. With impact velocities of up to $200 \mathrm{~m} / \mathrm{s}$, which is currently the technically realised maximum for hammer mills, the ratio $\mathrm{v}_{\mathrm{d}} / \mathrm{v}_{\mathrm{el}}$ is far smaller than unity and the loading can be considered as quasi-static, too. The initial size of the particles under investigation in this work lies in the range of $95 \mu \mathrm{m}$ to $8 \mathrm{~mm}$. It can be assumed that for these sizes, the initial flaw size of the particles is not yet influenced or limited by the initial particle size $[3,4]$. Therefore, the parameter $1_{\mathrm{i}} / \mathrm{x}$ in Eq. 1 will not have any influence on the comminution result for these coarse materials. The simplifications above lead to a reduced form of Eq. 1:

$$
\mathrm{P}_{\mathrm{B}}, \mathrm{B}=\mathrm{f}\left\{\mathrm{k}, \frac{\mathrm{W}_{\mathrm{V}} \cdot \mathrm{x}}{\beta_{\max }}, \frac{\mathrm{E}^{\prime} \cdot 1_{\mathrm{i}}}{\beta_{\max }}, \frac{\mathrm{H}}{\mathrm{E}^{\prime}}, \frac{\mathrm{E}^{\prime \prime}}{\mathrm{E}^{\prime}}, \Psi, v\right\}
$$

\subsection{Fracture Mechanic Model}

Weichert [5] introduced the Weibull statistics [6] to the field of comminution. The following modified approach is based on his procedure. The Weibull statistics is based on the principle of the weakest link in a chain. It gives the probability $\mathrm{P}_{\mathrm{B}}$ for the fracture of a chain which consists of $z$ links of strength $\sigma_{\mathrm{S}}$ when the load $\sigma$ is applied. $m$ is a free parameter of the probability distribution which is not related to a physical property in Weibull's approach.

$$
\mathrm{P}_{\mathrm{B}}=1-\exp \left\{-\mathrm{Z} \cdot\left(\frac{\sigma}{\sigma_{\mathrm{S}}}\right)^{\mathrm{m}}\right\}
$$

Crack initiation and particle breakage start at the circumference of the contact circle (simplifying Weichert's assumption of beginning breakage on the whole surface) [7, 8]. The highest tensile stresses occur at the circumference of the contact circle. Flaws and initial cracks in this area are subjected to these high stresses and are most likely to initiate particle failure. When a statistical distribution of flaws and micro-cracks is assumed, then the equivalent to the number of chain links needed for the application of Eq. 1 is the circumference or diameter a of the contact circle. It can be calculated from Hertz' theory according to Eq. 4. In Eq. 4, E and $\mathrm{E}_{\mathrm{T}}$ denote Young's modulus of the particle and the target, respectively, $v$ and $v_{\mathrm{T}}$ the Poisson ratio of the particle and the target, respectively, $\rho$ the particle density and $\mathrm{v}$ the impact velocity.

$$
\mathrm{a}=0,66 \cdot \mathrm{x} \cdot\left[1+\frac{\mathrm{E}}{\mathrm{E}_{\mathrm{T}}} \cdot \frac{1-\mathrm{v}_{\mathrm{T}}^{2}}{1-\mathrm{v}^{2}}\right]^{\frac{1}{5}} \cdot\left[\frac{1-\mathrm{v}^{2}}{\mathrm{E}} \cdot \rho \cdot \mathrm{v}^{2}\right]^{\frac{1}{5}}
$$

For impacting elastic spheres, the Hertz theory [9] 
atso albows for the calculation of the pressure distribution within the contact circle (Eq. 5). Gildemeister [7] Whowed that for impacting spheres, the stress field $\sigma$ within the sphere is similar for spheres of different diameters and proportional to the maximum pressure $\mathrm{p}_{\max }$ in the contact circle.

$$
\sigma \sim \mathrm{p}_{\max }=-0,84 \cdot \frac{\mathrm{E}}{1-v^{2}} \cdot\left[1+\frac{\mathrm{E}}{\mathrm{E}_{\mathrm{T}}} \cdot \frac{1-v_{\mathrm{T}}^{2}}{1-v^{2}}\right]^{-\frac{4}{5}} \cdot\left[\frac{1-v^{2}}{\mathrm{E}} \cdot \rho \cdot \mathrm{v}^{2}\right]^{\frac{1}{5}}
$$

Interpreting the load in Eq. 1 as stress and applying Eq. 5 also to the strength $\sigma_{\mathrm{S}}$, then the load term in Eq. 1 can be characterised by the equivalent velocities $\mathrm{v}$ and $\mathrm{v}_{\mathrm{S}}$ :

$$
\frac{\sigma}{\sigma_{\mathrm{S}}}=\left(\frac{v^{2}}{v_{\mathrm{S}}^{2}}\right)^{\frac{1}{5}}
$$

Inserting the above three equations into Eq. 1 leads to Eq. 7. It theoretically describes the breakage probability of elastic spheres. Vervoorn and Austin [10] have shown that the Hertz equations not only describe the impact force well for spherical particles, but also for irregularly shaped ones. Therefore Eq. 4 and Eq. 5 can be used as an approximation for the loading of irregular-shaped particles in a grinding process.

$$
\mathrm{P}_{\mathrm{B}}=1-\exp \left\{- \text { const. } \cdot \mathrm{x} \cdot\left[1+\frac{\mathrm{E}}{\mathrm{E}_{\mathrm{T}}} \cdot \frac{1-v_{\mathrm{T}}^{2}}{1-v^{2}}\right]^{\frac{1}{5}} \cdot\left[\frac{1-v^{2}}{\mathrm{E}} \cdot \rho \cdot \frac{v_{\mathrm{S}}^{2}}{2}\right]^{\frac{1}{5}} \cdot\left[\frac{v^{2} / 2}{v_{\mathrm{S}}^{2} / 2}\right]^{\frac{1+\mathrm{m}}{5}}\right\}
$$

Analogous to the principle of the weakest link in a chain, Eq. 1 can be applied to the repeated stressing of a particle taking into account the increase of the cumulated probability of particle breakage $P_{B}$ due to $\mathrm{k}$ successive impacts. Furthermore, in Eq. 7, the particle breakage begins at very small impact intensities which lead to a very small, but not negligible, value for the breakage probability. In own experiments as well as data published in literature [11-14], a significant threshold value for the impact energy can be observed. Below this threshold value no particle breakage occurs. Therefore the energy threshold $\mathrm{W}_{\mathrm{m} \text {,min }}$ is introduced which finally leads to Eq. 8 .

$$
\left.P_{B}=1-\exp \left\{- \text { const. } k \cdot x \cdot 1+\frac{E}{E_{T}} \cdot \frac{1-v_{T}^{2}}{1-v^{2}}\right]^{\frac{1}{5}} \cdot\left[\frac{1-v^{2}}{E} \cdot \rho \cdot \frac{v_{S}^{2}}{2}\right]^{\frac{1}{5}} \cdot\left[\frac{v^{2} / 2-W_{m, m i n}}{v_{S}^{2} / 2}\right]\right\}
$$

The quantitative application of Eq. 8 is difficult because the relevant material parameters are seldom known. Furthermore, it is not quite clear which material strength $\sigma_{\mathrm{S}}$ or equivalent velocity $\mathrm{v}_{\mathrm{S}}$, respectively, have to be used as most of the classic mechanical strength parameters such as tension or impact strength are strongly dependent on the test procedure. Further work will be carried out on this problem.

\subsection{Derivation of Relevant Material Parameters}

The two different approaches which lead to Eq. 2 and Eq. 8, respectively, can be united to form a single equation describing the breakage probability for particles of different materials. In Eq. 2, $\beta_{\max }, E^{\prime}, E^{\prime \prime}, H, 1_{i}$ and $v$ denote the fracture and deformation mechanical parameters which are appropriate, e.g. for geometrically well-defined problems. In the case of the comminution of particles, their quantitative application is difficult. Therefore, we will introduce two new parameters, $\mathrm{f}_{\mathrm{Mat}}^{*}$ and $\mathrm{W}_{\mathrm{V}, \mathrm{i}}$ here, which are related to $\beta_{\max }, E^{\prime}, E^{\prime \prime}, H, 1_{i}, v$ and $\Psi$, but which can be applied and determined directly by comminution experiments. They can be interpreted as mean particle properties which take the material properties of the particle and irregular particle shape fully into account. $f_{\text {Mat. }}^{*}$ characterises the resistance of the particle material against the volume-specific external load energy. $W_{V, i}$ is a measure for the volume-specific energy which is required to initiate fracture at an existing flaw of size $1_{i}$. Both parameters relate the external load during impact, characterised by the specific impact energy $W_{\mathrm{V}}$, to the internal particle strength. Together with a rearrangement of the dimensionless variables this leads to a simplified form of Eq. 2:

$$
\begin{aligned}
& \mathrm{P}_{\mathrm{B}}, \mathrm{B}=\mathrm{f}\left\{\mathrm{f}_{\text {Mat. }}^{*} \cdot\left(\mathrm{W}_{\mathrm{V}} \cdot \mathrm{x}, \mathrm{W}_{\mathrm{V}, \mathrm{i}} \cdot 1_{\mathrm{i}}\right)\right\} \text { with } \\
& \mathrm{f}_{\text {Mat. }}^{*} \cdot \beta_{\max }=\mathrm{f}_{1}\left(\frac{\mathrm{E}^{\prime \prime}}{\mathrm{E}^{\prime}}, \frac{\mathrm{H}}{\mathrm{E}^{\prime}}, v, \Psi\right) \\
& \frac{\mathrm{W}_{\mathrm{V}, \mathrm{i}} \cdot 1_{\mathrm{i}}}{\mathrm{E}^{\prime} \cdot 1_{\mathrm{i}}}=\mathrm{f}_{2}\left(\frac{\mathrm{E}^{\prime \prime}}{\mathrm{E}^{\prime}}, \frac{\mathrm{H}}{\mathrm{E}^{\prime}}, v, \Psi\right)
\end{aligned}
$$

Eq. 8 and Eq. 9 originate from different approaches but describe the same phenomenon: particle breakage. They can be united when the main influencing factors and dimensionless groups are compared. As the mass-specific impact energy $\mathrm{W}_{\mathrm{m} \text {,kin }}$ and the volume-specific impact energy $\mathrm{W}_{\mathrm{V}}$ are directly proportional to each other, Eq. 8 and 9 can only match if the free, adjustable exponent $\mathrm{m}$ of the Weibull distribution equals 4 . Then, both equations show the same combined influence of the product of specific energy and particle size on the breakage probability. There- 
fore, $w=4$ will be used in the following leading to:

$$
P_{B}=1-\exp \left\{- \text { const.k } x \cdot\left[1+\frac{E}{E_{T}} \cdot \frac{1-v_{T}^{2}}{1-v^{2}}\right] \frac{1}{5} \cdot\left[\frac{1-v^{2}}{E} \cdot p \cdot \frac{v_{S}^{2}}{2}\right] \frac{1}{5} \cdot\left[\frac{W_{m, k i n}-W_{m, \min }}{v_{S}^{2} / 2}\right]\right\}
$$

Furthermore, comparing Eq. 9 with Eq. 10 shows that the threshold energy $\mathrm{W}_{\mathrm{m} \text {,min }}$ has to be size-dependent. The product $\mathrm{xW}_{\mathrm{m} \text {,min }}$ relates to $\mathrm{l}_{\mathrm{i}} \mathrm{W}_{\mathrm{Vi}}$ and because both, $1_{\mathrm{i}}$ and $\mathrm{W}_{\mathrm{V}, \mathrm{i}}$, are independent of the particle size, $\mathrm{xW}_{\mathrm{m}, \mathrm{min}}$ has to be a material constant, too. $\mathrm{f}_{\text {Mat. }}^{*}$ as well as the factor $\left[1+\frac{\mathrm{E}}{\mathrm{E}_{\mathrm{T}}} \cdot \frac{1-\mathrm{v}_{\mathrm{T}}^{2}}{1-\mathrm{v}^{2}}\right]^{\frac{1}{5}} \cdot\left[\frac{1-v^{2}}{\mathrm{E}} \cdot \rho \cdot \frac{v_{\mathrm{S}}^{2}}{2}\right]^{\frac{1}{5}} \cdot \frac{1}{v_{\mathrm{S}}^{2} / 2}$ is purely dependent on material properties and independent of the stressing conditions and particle size, thus again showing agreement between the two approaches. Finally, Eq. 10 can be written for $\mathrm{k}$ successive impacts with the single mass-specific impact energy $\mathrm{W}_{\mathrm{m} \text {,kin }}$ and using the new material parameters

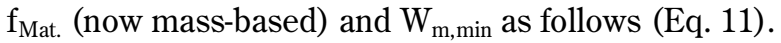
$f_{\text {Mat. }}$ denotes the resistance of the particle material against the external load $\mathrm{W}_{\mathrm{m} \text {,kin }}$, and $\mathrm{W}_{\mathrm{m} \text {,min }}$ is a specific threshold energy for a particle of size $\mathrm{x}$, which has to be exceeded by the specific impact energy in order to cause particle breakage. Below this threshold value, particle breakage does not occur.

$$
\mathrm{P}_{\mathrm{B}}=1-\exp \left\{-\mathrm{f}_{\text {Mat. }} \cdot \mathrm{x} \cdot \mathrm{k} \cdot\left(\mathrm{W}_{\mathrm{m}, \mathrm{kin}}-\mathrm{W}_{\mathrm{m}, \min }\right)\right\}
$$

Based on two different and independent approaches, the similarity considerations and the fracture mechanical model, an analytical function for the breakage probability is derived [24, 25]. Simplifying both approaches leads to the same main parameters determining particle breakage: the product of impact energy and initial particle size, the newly introduced material or particle parameter $\mathrm{f}_{\mathrm{Mat}}$ and the size-independent threshold value $\mathrm{xW}_{\mathrm{m} \text {,min }}$. According to the model assumption, $\mathrm{f}_{\text {Mat. }}$ and $\mathrm{xW}_{\mathrm{m} \text {,min }}$ comprise all particle properties and should therefore describe the material influence on the comminution result.

\section{SINGLE PARTICLE EXPERIMENTS}

Single particle comminution experiments were carried out to validate the model and to determine the introduced material parameters. Fig. 1 shows the single particle impact device used for the experiments. It was developed by Schönert [15]. A vibration feeder transports single particles from the feed chamber to the disc-shaped rotor. There, the particles are accelerated in radial channels by the centrifugal force. After reaching the outer diameter of the rotor, they are ejected with a final velocity consisting of a radial and a tangential component, both equal to the circumferential speed of the rotor. As both feeder and grinding chamber are evacuated in order to avoid the disturbing influence of any air flows, the impact velocity $\mathrm{v}$ of the particles on the target ring is given by the ejecting velocity from the rotor, and because of its sawtooth shape, the particles impact at an angle of $90^{\circ}$. For the single particle tests shown here, impact velocities from 10 to $140 \mathrm{~m} / \mathrm{s}$ were realised at an ambient temperature. At the end of a single test, the size distribution of the product particles was determined by sieve size analysis. After the analysis, the product particles were stressed again under the same conditions in order to simulate multiple impacts. This procedure was repeated up to five times. Five different polymers (polymethyl methacrylate: PMMA G55, G7 and G88 from BASF AG and Agomer $\mathrm{GmbH}$, and polystyrene: PS $168 \mathrm{~N}$ and $144 \mathrm{C}$ from BASF AG) with different molecular weight distributions which result in different mechanical properties were used. Furthermore, two crystalline materials (ammonia sulphate and potassium alum), limestone, two powder coatings (epoxy and polyester-based), and glass spheres were investigated. Narrow size fractions of the feed material were produced by sieving. In each experiment, approximately 2500 particles were stressed in order to obtain statistically reliable results.

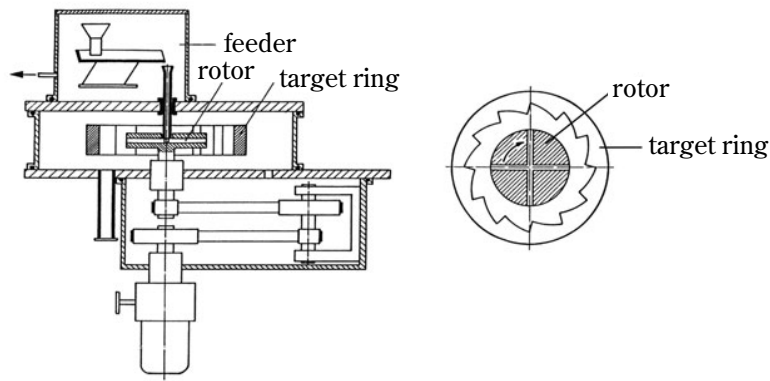

Fig. 1 Single particle impact device [15]

\section{EXPERIMENTAL RESULTS}

Eq. 11 accounts for the influence of the initial particle size on fracture. Fig. 2 shows the breakage probability $\mathrm{P}_{\mathrm{B}}$ of glass spheres covering a size range of almost two decades. The data were taken from literature (open symbols and dashed lines [16], filled sym- 
Pe

bots aqu solid lines [17]). The difference in breakage $d{ }^{2}$ forthe different sizes is obvious. For the same energy winput smaller particles exhibit a smaller breakage probability. This can be explained by the fact that for smaller particles the circumference of the contact area is smaller and therefore fewer flaws are affected by the critical tensile stress.

If $P_{B}$ is plotted versus $x \cdot W_{m, k i n}$ (Fig. 3), all curves overlap and show the predicted influence of impact energy and initial particle size in Eq. 11. Approximately, the energy threshold $\mathrm{W}_{\mathrm{m} \text {,min }}$ is inversely proportional to the initial particle size, leading to a constant value for $\mathrm{xW}_{\mathrm{m}, \min }$ as predicted by the model. The threshold value can be determined in Fig. 3 as the intercept of the curve with the abscissa. The lines in Fig. 2 and Fig. 3 are fits of Eq. 11 to the experimental data. They show good agreement between theory and experiment.
Fig. 4 shows the breakage probability for two different polymers (PMMA G55 and G88). The initial particle size was a narrow sieve size fraction between 2.0 and $2.5 \mathrm{~mm}$. The lines in Fig. 4 are again fits of Eq. 11 to the experimental data. Both materials follow the model well. The results of the multiple impacts agree well with Eq. 11 when they are plotted as a function of the total net energy $\mathrm{k} \cdot\left(\mathrm{W}_{\mathrm{m}, \mathrm{kin}}-\mathrm{W}_{\mathrm{m}, \mathrm{min}}\right)$.

Fitting Eq. 11 to the breakage data of single particle impact tests gives the material parameter $\mathrm{f}_{\text {Mat. }}$ and the size-independent threshold value $\mathrm{xW}_{\mathrm{m}, \min }$ for each material. $\mathrm{f}_{\text {Mat }}$ and $\mathrm{xW}_{\min }$ are approximately inversely proportional to each other. Brittle materials are characterised by high values of $f_{\text {Mat }}$, more ductile materials show small values of $f_{\text {Mat }}$. For the investigated materials, these values are given in Tab. 1.

When the breakage data are plotted according to the probability distribution (Eq. 11) as a function of

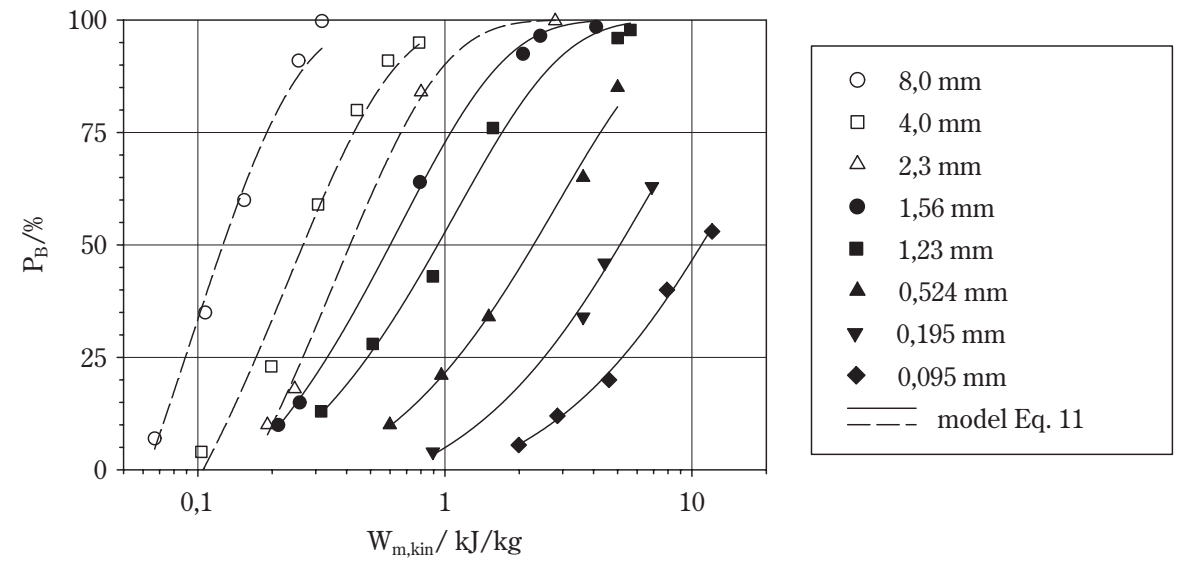

Fig. 2 Breakage probability of glass spheres of different sizes [16, 17]

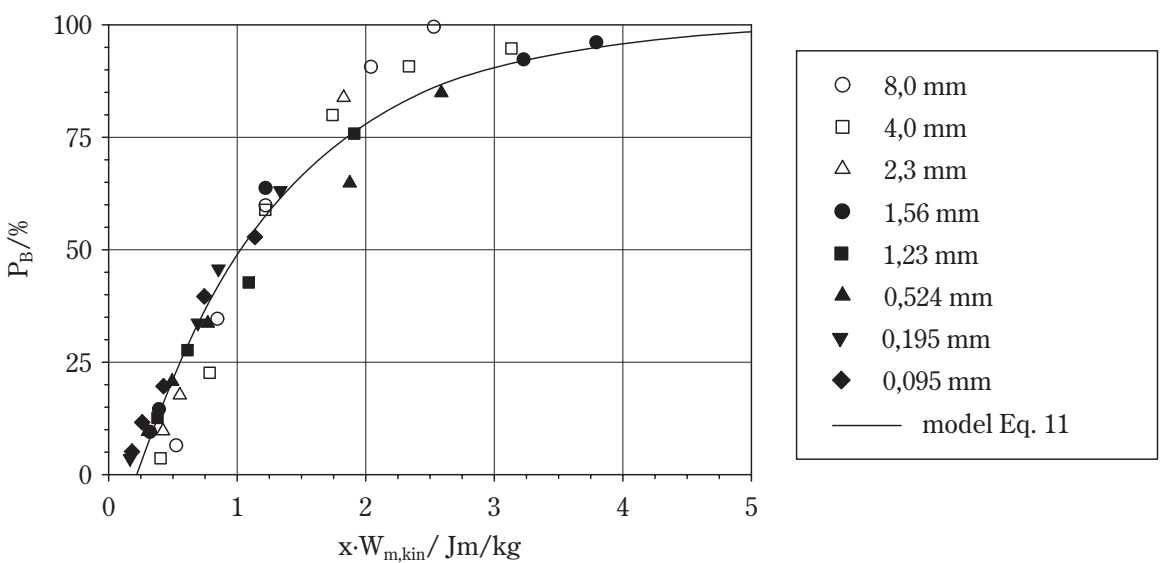

Fig. 3 Breakage probability of glass spheres of different sizes [16, 17] 


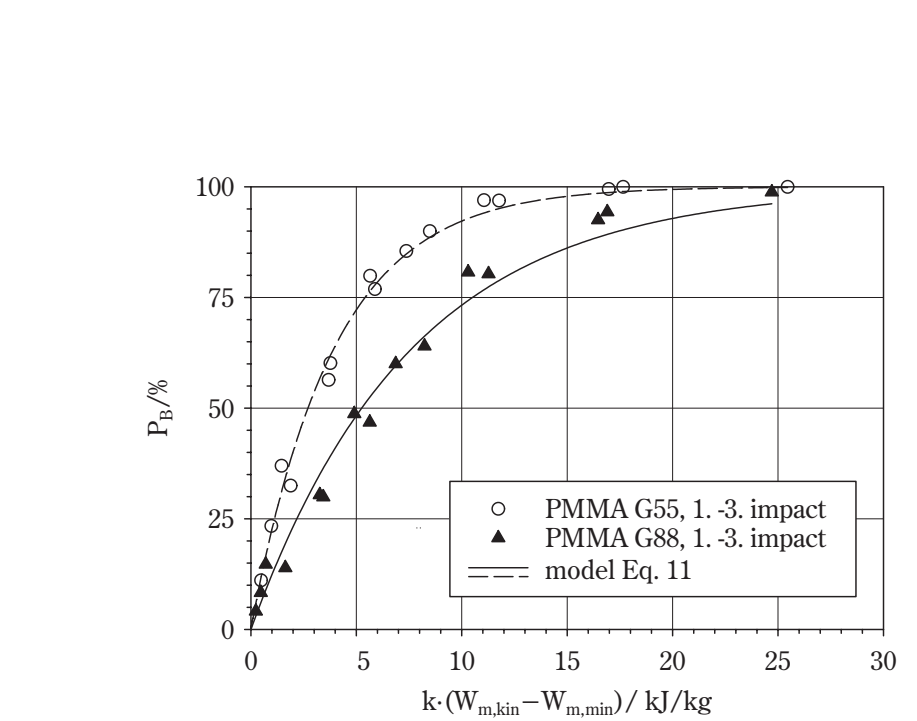

Fig. 4 Breakage probability of PMMA as a function of the total net impact energy

Table 1 Material parameters $\mathrm{f}_{\text {Mat. }}$ and $\mathrm{xW}_{\mathrm{m} \text {,min }}$ determined from single particle tests

\begin{tabular}{|c|c|c|}
\hline & $\mathrm{f}_{\text {Mat. }} / \mathrm{kg} / \mathrm{Jm}$ & $\mathrm{xW}_{\mathrm{m}, \mathrm{min}} / \mathrm{Jm} / \mathrm{kg}$ \\
\hline PMMA G88 & 0.059 & 3.541 \\
\hline PMMA G7 & 0.095 & 5.898 \\
\hline PMMA G55 & 0.115 & 2.957 \\
\hline PS 168N & 0.118 & 5.410 \\
\hline PS 144C & 0.125 & 3.427 \\
\hline limestone & 0.327 & 0.520 \\
\hline ammonia sulphate & 0.884 & 0.126 \\
\hline glass spheres & 0.944 & 0.297 \\
\hline potassium alum & 1.491 & 0.147 \\
\hline powder coating (polyester) & 2.299 & 0.018 \\
\hline powder coating (epoxy) & 5.266 & 0.005 \\
\hline
\end{tabular}

the product of total net impact energy $\mathrm{k} \cdot\left(\mathrm{W}_{\mathrm{m}, \mathrm{kin}}\right.$ $-\mathrm{W}_{\mathrm{m}, \mathrm{min}}$ ), the initial particle size $\mathrm{x}$ and material parameter $\mathrm{f}_{\text {Mat. }}$ Fig. $\mathbf{5}$ is obtained. For all materials under investigation, i.e. three PMMA, two PS, limestone, glass spheres, two crystalline materials and two powder coatings, a single curve describes the breakage probability. The experimental data is well within a deviation of $+/-15 \%$ of Eq. 11 . The main conclusion which can be drawn from these results is that the influence of the main parameters stress intensity (impact energy) and stress frequency (impact number), initial particle size and material properties are quantified correctly by the developed model. The plot in Fig. $\mathbf{5}$ can be seen as a mastercurve describing the breakage probability of various materials. The product $\mathrm{f}_{\text {Mat. }} \cdot \mathrm{x} \cdot \mathrm{k} \cdot\left(\mathrm{W}_{\mathrm{m}, \mathrm{kin}}-\mathrm{W}_{\mathrm{m}, \min }\right)$ can be interpreted as a dimensionless stressing parameter. For the first time, measurable material properties, i.e. the material parameter $\mathrm{f}_{\mathrm{Mat}}$ and the threshold value $\mathrm{xW}_{\mathrm{m} \text {,min }}$ which describe the grinding performance of different materials quantitatively, can be determined and thus permit a systematic distinction to be made between different materials.

\section{MODELLING OF GRINDING IN IMPACT MILLS}

The main objective for the modelling of impact mills with population balances here was that of a clear separation of the different influences of material properties, machine-specific features and operating conditions in order to be able to interpret the results. It was therefore assumed that the grinding process can be described separately by a machine and a material

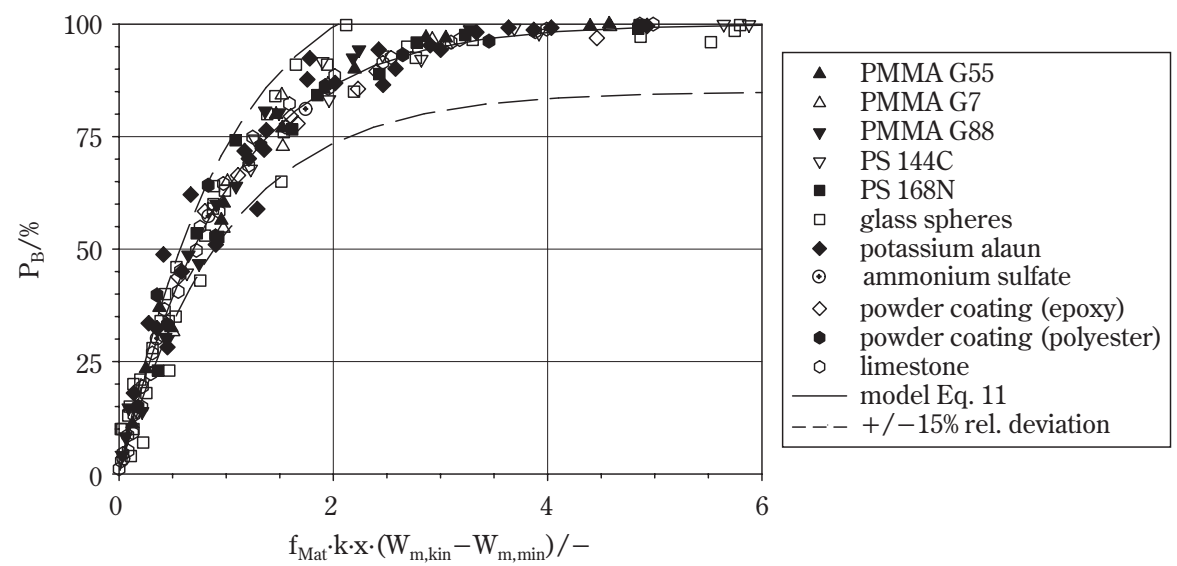

Fig. 5 Mastercurve for the breakage probability of various materials 
is

fanction $[18,25]$. The machine function comprises the type of mill as well as all the operating conditions. $W^{N}$ By choosing the mill, the kind of particle stressing is defined. The operating conditions of the mill on the other hand determine the number of stress events, their intensity and the distribution of both. Operating conditions can be characterised, e.g. by the speed of revolutions, the air flow rate and the solids loading. For rotor impact mills, the speed of the hammers correlates with the stress intensity. The number of stress events depends on the residence time distribution of the particles in the mill. The experimental set-up, the structure of the model, the applied population balance and the material function is described below.

\subsection{Experimental Set-Up}

The experiments with the air classifier mill were carried out with a Hosokawa ACM 2 with a rotor diameter of $177 \mathrm{~mm}$ (Fig. 6) at Hosokawa Micron $\mathrm{GmbH}$ in Cologne, Germany. The particles are fed to the grinding zone by a rotary valve. There they are stressed by the grinding pins and then transported by the main air to the impeller wheel classifier. The shroud ring permits controlled transport by separating the grinding zone from the classifying zone. Material that is fine enough leaves the mill through the classifier with the main air, whereas coarse material is rejected and transported by the internal circulation back to the grinding zone. There it is stressed again. In the experiments, the revolution speed of the rotor (5787 to $10417 \mathrm{rpm}$, equivalent to circumferential velocities from 50 to $90 \mathrm{~m} / \mathrm{s}$ ), the revolution speed of the classifier (1270 to $6500 \mathrm{rpm}$ ) and the solids loading ( 0.056 to $0.1350 \mathrm{~kg}$ solids $/ \mathrm{kg}$ of air) were varied. The air flow was monitored and kept at a constant value. The ground product was limestone.

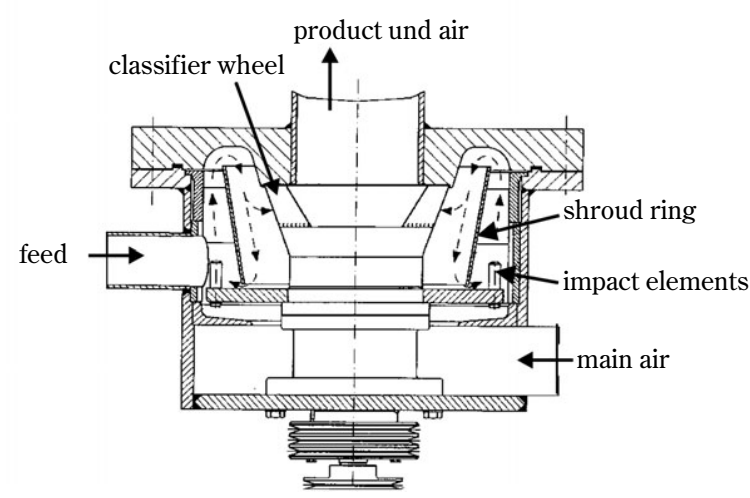

Fig. 6 Air classifier mill ACM 2

\subsection{Structure of the Model}

A simple structure for the model of the mill was chosen. It is shown in Fig. 7. The air classifier mill consists of a grinding zone and a classifying zone connected by a more or less defined particle transport. Grinding and classifying were transferred to two separate units in the model mill. A third unit, the hold-up, was added to mix the feed with the coarse material which was rejected by the classifier. Material leaving the grinding zone reaches the classifier and if small enough, is removed from the system or if too big, is recirculated to the hold-up. There it is mixed with the feed and again transported to the grinding zone. The recirculation flux is a free internal parameter of the model and not predetermined nor adjusted.

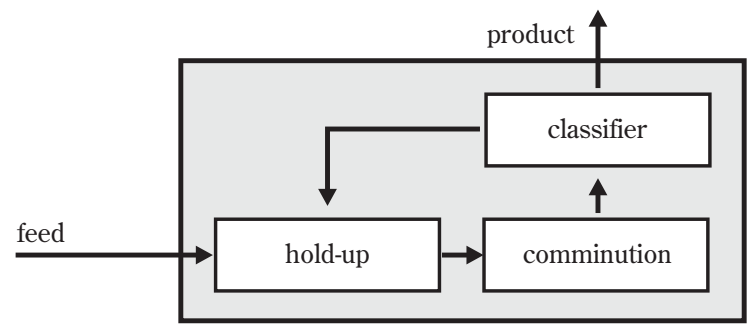

Fig. 7 Structure of the mill model

\subsection{Population Balance}

The change of the particle mass in a discrete size band during a discrete grinding step, e.g. after a single stressing event, is given by the mass leaving the size band as fragments and the mass entering the size band as fragments from larger sizes (Eq. 12, [19]). The mass leaving a size band i per unit of time is given by the product of the particle mass $\mathrm{m}_{\mathrm{i}}$ in the size band multiplied by the breakage probability $\mathrm{P}_{\mathrm{B}, \mathrm{i}}$. Entering class $i$ from a bigger size $j$ is the mass $m_{j}$ inside class $j$ multiplied with the breakage probability $\mathrm{P}_{\mathrm{B}, \mathrm{j}}$ and the mass transfer function $\mathrm{b}_{\mathrm{i}, \mathrm{j}}$, which denotes the fraction of fragments breaking from class $j$ into the size band $i$. Herein $i=1$ denotes the largest and $\mathrm{i}=\mathrm{N}$ the smallest particle size, respectively. The mass transfer function $b_{i, j}$ can be calculated from the breakage function $\mathrm{B}_{\mathrm{i}, \mathrm{j}}$.

$$
\Delta m_{i}=\sum_{j=1}^{i-1} m_{j} \cdot b_{i j} \cdot P_{B, j}-m_{i} \cdot P_{B, i} \text { with } b_{i, j}=B_{i-1, j}-B_{i, j}
$$

Taking into account not only a single size band $\mathrm{m}_{\mathrm{i}}$ but all particle sizes leads to the particle size distribu- 
tion rector $\underline{m}$. The particle size distribution $\underline{m}+\Delta \underline{m}$ after a.discrete grinding step can then be calculated from the particle size distribution before the interval $\underline{m}$ when the balance according to Eq. 12 is calculated for all size intervals. This leads to a set of equations which can be written in vector form with $\underline{\underline{Z}}$ being the comminution matrix (Eq. 13).

$$
\underline{\mathrm{m}}+\Delta \underline{\mathrm{m}}=\underline{\underline{Z}} \cdot \underline{\mathrm{m}}, \underline{\underline{Z}}=\left[\begin{array}{cccc}
1-\mathrm{P}_{\mathrm{B}, 1} & 0 & \cdots & 0 \\
\mathrm{~b}_{21} \cdot \mathrm{P}_{\mathrm{B}, 1} & 1-\mathrm{P}_{\mathrm{B}, 2} & 0 & 0 \\
\vdots & \vdots & \ddots & \vdots \\
\mathrm{b}_{\mathrm{N} 1} \cdot \mathrm{P}_{\mathrm{B}, 1} & \mathrm{~b}_{\mathrm{N} 2} \cdot \mathrm{P}_{\mathrm{B}, 2} & \cdots & 0
\end{array}\right]
$$

It can be shown $[20,21]$ that the comminution result after $\mathrm{n}$ multiple stressing events can be calculated by n-times multiplying the particle size vector $\underline{m}(0)$ prior to the stressing with the comminution matrix $\underline{\underline{Z}}$. This leads to the final form of the population balance which was implemented in the model:

$$
\underline{\mathrm{m}}(\mathrm{n})=\prod_{1=1}^{\mathrm{n}} \underline{\underline{Z_{1}}} \cdot \underline{\mathrm{m}}(0)
$$

The cut size of the air classifier mill was calculated by the equilibrium of drag and centrifugal force at the impeller wheel. The values were taken as values for the median size $x_{50, t}$ of the separation curve. The sharpness of cut $\kappa=\mathrm{x}_{25, \mathrm{t}} / \mathrm{x}_{75, \mathrm{t}}$ was assumed to be 0.5 , as recommended for technical classifiers [22].

\subsection{Material Function}

Eq. 11 was implemented in the model for the breakage probability. It allows for a clear separation between material properties and the stressing conditions. The fragment size distribution $\mathrm{B}$ was found to be in good agreement with an adjusted power law according to Eq. 15. Herein $\mathrm{x}$ denotes the size of the mother particles and $y$ the fragment size. The parameter q denotes the power law exponent.

$$
\mathrm{B}=\left(\frac{\mathrm{x}}{\mathrm{y}}\right)^{\mathrm{q}} \cdot \frac{1}{2} \cdot\left\{1+\tanh \left(\frac{\mathrm{y}-\mathrm{y}^{\prime}}{\mathrm{y}^{\prime}}\right)\right\} \text { with } \mathrm{q}=\mathrm{c} \cdot \mathrm{v}+\mathrm{d}
$$

As the power law fades only slowly to zero for small particle sizes, it always leads to a certain error by creating fines with unrealistically small sizes. The second factor forces the power law to fade more rapidly, reducing the effect of artificially created fines. The value $\mathrm{y}^{\prime}$ is the fragment size from which point on the additional fading becomes significant. Logically, its value is chosen close to the minimal particle size expected by fragmentation, which can be estimated from [23]. It was possible to show from the results of single particle impact tests that the exponent q of the heuristic power law could be approximated well by a linear function of the impact velocity $\mathrm{v}$, which leads to a reduction in free model parameters. The linear function can be determined separately by single particle tests, thus again separating mill and material function. The parameters of the breakage function for the materials under investigation are given in Tab. 2 .

Table 2 Material parameters for the simulation

\begin{tabular}{|c|c|c|c|}
\hline & $\mathrm{c} / \mathrm{s} / \mathrm{m}$ & $\mathrm{d} /-$ & $\mathrm{y}^{\prime} / \mu \mathrm{m}$ \\
\hline limestone & -0.0050 & 0.70 & 1 \\
\hline
\end{tabular}

\section{EXPERIMENTAL AND SIMULATION RESULTS}

Fig. 8 shows typical results for the simulation of the air classifier mill. A good agreement between experimental results and simulation can be observed. Although no experimental data were available on the separation curve of the classifier, the calculated curve fits in well. Slight differences occur for the fines. The influence of the velocity of the grinding rotor and the speed of the impeller wheel classifier on the parameter $\mathrm{n}$ is given in Fig. 9. The model parameter $\mathrm{n}$, a measure for the stressing frequency, decreases with increasing grinding rotor velocity. The parameter also decreases with increasing solids loading, whereas it is almost unaffected by the classifier wheel speed.

For the lower classifier speeds (1270 and 2540 rpm), the hold-up normalised by the corresponding mass of feed per unit of time is close to unity (Table 3). Most particles are small enough to leave the mill after the first passage through the grinding zone. In this range, the hold-up increases only slightly with increasing classifier speed. For higher classifier speeds, the hold-up increases significantly. Up to 2.6 times the amount of feed per unit of time is kept in the hold-up when the classifier operates at $6500 \mathrm{rpm}$. As expected, the finer cut size leads to a higher internal recirculation. The mill effectively operates with recirculation, which is in agreement with the structure of the mill shown in Fig. 7. There, the separation of grinding zone and classifying zone by the shroud ring can be seen.

The solids loading (mass flow of solids per mass flow of air) exhibits an influence that is similar to that of the classifier speed. Increasing the loading from small values, close to the conditions of single particle tests, up to $0.135 \mathrm{~kg} / \mathrm{kg}$ and therefore approaching the conditions of production mills, leads to an 


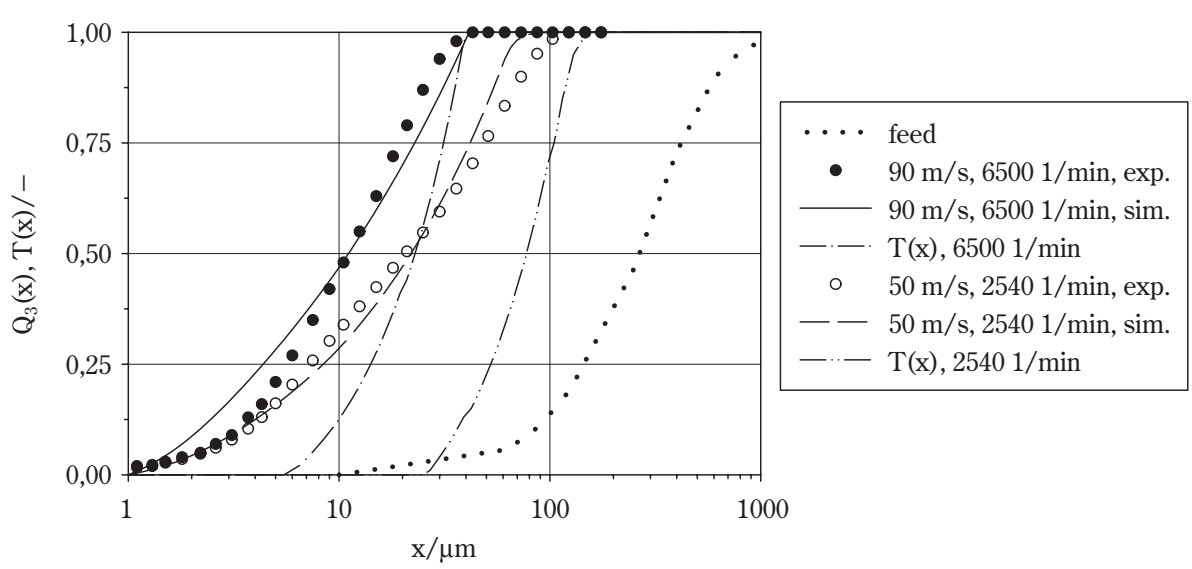

Fig. 8 Representative simulation results for the air classifier mill

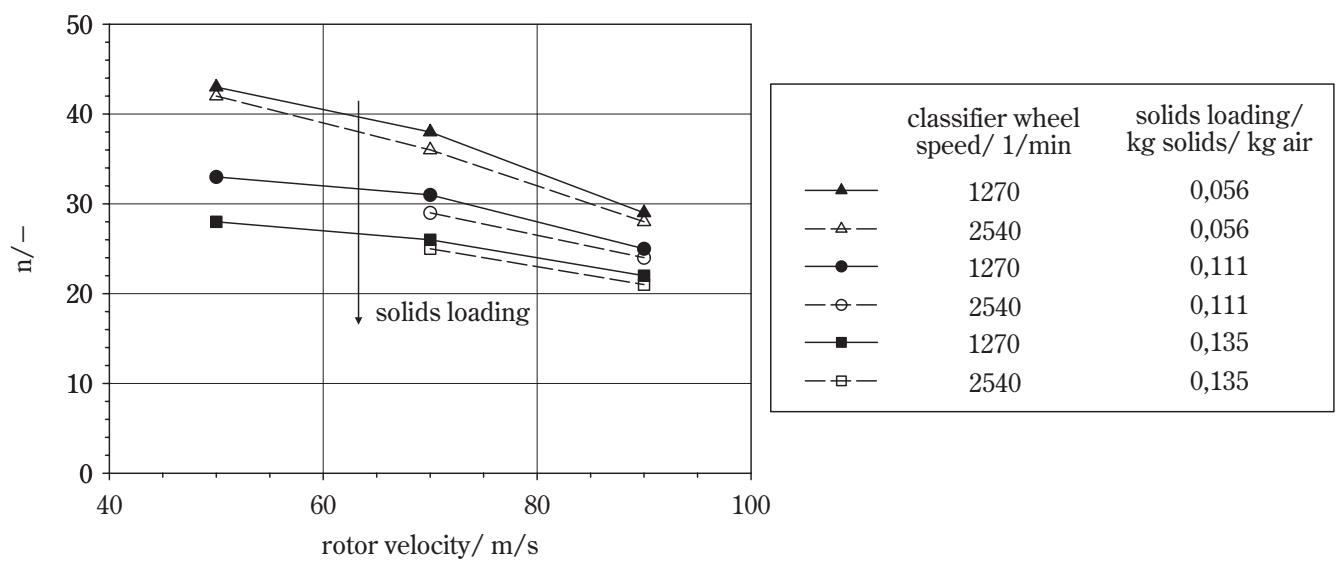

Fig. 9 Influence of the grinding rotor velocity on model parameters

Table 3 Hold-up as a function of the classifier wheel speed

\begin{tabular}{|l|c|c|c|c|c|}
\hline classifier wheel speed [rpm] & 1270 & 2540 & 3800 & 5075 & 6500 \\
\hline normalised hold-up / - & 1.00 & 1.10 & 1.16 & 1.55 & 2.62 \\
\hline
\end{tabular}

increase of the hold-up and reduces the parameter $\mathrm{n}$. The agreement between simulation and experiment is still good and the simulation of even higher concentrations seems possible.

Similar investigations were carried out for sieve hammer mills. In this case, two types of PMMA were studied. We found a very good agreement again between our model and the experimental data.

\section{CONCLUSIONS AND PERSPECTIVES}

Two approaches describing the influence of material properties, particle size and external load on the result of impact comminution have been presented. It is shown that both lead to the same influencing parameters, namely the product of initial particle size, total mass-specific net impact energy and a newly introduced material strength parameter. The breakage probability is described by a single mastercurve comprising the breakage behaviour of different materials (polymers, limestone, crystals, glass) of various sizes $(95 \mu \mathrm{m}$ to $8 \mathrm{~mm})$ for multiple impacts. For the first time, measurable material properties describing the comminution performance of different materials have been derived and determined experimentally. These material parameters permit a quantitative dif- 
feren ratipa. between various products and enable a aomparison of different materials of different size.

These material parameters were applied to a simple model for the simulation of grinding different products in impact mills. A good agreement between simulation results and experiments was achieved while retaining a clear distinction between material and operating parameters. The material parameters were determined independent of the machine properties by single particle comminution tests. The free adjustable model parameter $\mathrm{n}$, which correlates to the stressing frequency, showed systematic and reasonable trends with the operating parameters of the mills and could be explained by physical effects. Sieve hammer mills as well as air classifier mills can be simulated by the help of externally measured material functions using measurable operating parameters to describe the stressing conditions in the mill. A safe simulation of operating conditions within the range experimentally covered and a reasonably reliable extrapolation outside is possible. Because the material properties were determined independent of the mill, they can be utilised in similar applications for other types of impact mills.

In future work, it has to be examined whether experimental results for the breakage function can be explained by the product $\mathrm{f}_{\text {Mat. }} \cdot \mathrm{x} \cdot \mathrm{k} \cdot\left(\mathrm{W}_{\mathrm{m}, \mathrm{kin}}-\mathrm{W}_{\mathrm{m}, \mathrm{min}}\right)$, too. A correlation of the comminution parameters to basic parameters from fracture mechanical considerations will be investigated. The population balance model presented here showed good agreement between simulation and experimental results, and the obtained model parameters could be explained reasonably, but no information based on experimental studies on the particle transport and the resulting stressing conditions is available so far. This shortcoming has to be overcome, and a more sophisticated and predictive modelling is aimed for.

\section{ACKNOWLEDGEMENTS}

This project is partly sponsored by the German Federal Ministry of Economics and Technology, grant number AiF-No. 12680 N. The authors appreciate the given support. The authors would like to thank Hosokawa Micron GmbH in Cologne, Germany, for carrying out the milling experiments. Furthermore, BASF AG strongly supported the simulation by providing the simulation tool. The authors greatly appreciate this support.

\section{NOMENCLATURE}

a diameter of contact circle [m]

B cumulative breakage function [-]

$\mathrm{b}_{\mathrm{i}, \mathrm{j}} \quad$ mass transfer coefficient $\quad[-]$

c parameter [s/m]

d parameter [-]

$\mathrm{E}, \mathrm{E}_{\mathrm{T}}$ Young's modulus of particle and target material, respectively

$[\mathrm{Pa}]$

$\mathrm{E}^{\prime}, \mathrm{E}^{\prime \prime}$ storage and loss modulus, respectively $\quad[\mathrm{Pa}]$

$\mathrm{f}, \mathrm{f}_{1}, \mathrm{f}_{2}$ function

$\mathrm{f}_{\text {Mat. }} \quad$ mass-based material strength parameter $[\mathrm{kg} / \mathrm{Jm}]$

$\mathrm{f}_{\text {Mat. }}^{*} \quad$ volume-based material strength parameter

$\mathrm{H}$ hardness $[\mathrm{Pa}]$

$\mathrm{k}$ number of impacts [-]

$1_{\mathrm{i}}$ inherent flaw size [m]

$\mathrm{m} \quad$ parameter of Weibull distribution [-]

$\mathrm{m}_{\mathrm{i}} \quad$ mass of particles in size band $\mathrm{i} \quad[\mathrm{kg}]$

$\underline{m} \quad$ vector of particle size distribution [kg]

$\mathrm{n} \quad$ model parameter correlating to stressing frequency

[-]

$\mathrm{P}_{\mathrm{B}} \quad$ breakage probability $\quad[-]$

$\mathrm{p}_{\max }$ maximum pressure in contact circle $[\mathrm{Pa}]$

q power law exponent [-]

$\mathrm{Q}_{3}(\mathrm{x})$ cumulative particle size distribution [-]

$\mathrm{T}(\mathrm{x})$ separation curve [-]

$\mathrm{v}$ impact velocity [m/s]

$\mathrm{v}_{\mathrm{d}}$ deformation velocity [m/s]

$\mathrm{v}_{\mathrm{el}} \quad$ propagation velocity of elastic waves $[\mathrm{m} / \mathrm{s}]$

$\mathrm{v}_{\text {fract }}$ propagation velocity of cracks $[\mathrm{m} / \mathrm{s}]$

$\mathrm{v}_{\mathrm{S}}$ strength [m/s]

$\mathrm{W}_{\mathrm{m} \text {,kin }}$ mass-specific impact energy $\quad[\mathrm{J} / \mathrm{kg}]$

$\mathrm{W}_{\mathrm{m} \text {,min }}$ mass-specific threshold energy $\quad[\mathrm{J} / \mathrm{kg}]$

$\mathrm{W}_{\mathrm{V}} \quad$ volume-specific stressing energy $\quad\left[\mathrm{J} / \mathrm{m}^{3}\right]$

$\mathrm{W}_{\mathrm{V}, \mathrm{i}} \quad$ volume-specific energy for activation of a inherent flaw

$\left[\mathrm{J} / \mathrm{m}^{3}\right]$

$\mathrm{x} \quad$ initial particle size $[\mathrm{m}]$

y fragment size [m]

$\mathrm{y}^{\prime} \quad$ fragment size for additional fading $\quad[\mathrm{m}]$

$Z \quad$ number of chain links [-]

$\underline{\underline{Z}} \quad$ comminution matrix $[-]$

$\beta_{\max } \quad$ crack extension energy $\quad\left[\mathrm{J} / \mathrm{m}^{2}\right]$

$v, v_{\mathrm{T}} \quad$ Poisson ratio of particle and target material, respectively

$\rho \quad$ particle density $\quad\left[\mathrm{kg} / \mathrm{m}^{3}\right]$

$\sigma$ load $[\mathrm{Pa}]$

$\sigma_{\mathrm{S}} \quad$ strength $\quad[\mathrm{Pa}]$

$\Psi$ shape factor [-] 
erates, Powder Technology, 105, 1999, 66-73

[14] Zverev, S.: Comminution of materials by free impact, Russian Chemical Industry, 25 (2), 1993, 31-36

[15] Marktscheffel, M.; Schönert, K.: Liberation of composite particles by single particle compression, shear and impact loading, Preprints of the 6. European Symposium Comminution, Nürnberg 1986, 29-45

[16] Priemer, J.: Untersuchungen zur Prallzerkleinerung von Einzelteilchen, PhD-Thesis Technische Hochschule Karlsruhe 1964

[17] Behrens, D.: Über die Prallzerkleinerung von Glaskugeln und unregelmäßig geformten Teilchen aus Schwerspat, Kalkstein und Quarzsand im Korngrößenbereich von 0,1 und 1,5 mm, PhD-Thesis Technische Hochschule Karlsruhe 1965

[18] Peukert, W.; Vogel, L.: Comminution of Polymers An Example of Product Engineering, Chemical Engineering and Technology, 24 (9), 2001, 945-950

[19] Reid, K.: A Solution to the Batch Grinding Equation, Chemical Engineering Science, 20, 1965, 953-963

[20] Müller, F.; Polke, R.; Schäfer, M.: Model-Based Evaluation of Grinding Experiments, Powder Technology, 105, 1999, 243-249

[21] Berthiaux, H.: Analysis of Grinding Processes by Markov Chains, Chemical Engineering Science, 55, 2000, 4117-4127

[22] Löffler, F.; Raasch, J.: Grundlagen der Mechanischen Verfahrenstechnik, Vieweg Verlag, Wiesbaden 1992

[23] Schönert, K.: Size Reduction, in: Ullmann's Encyclopedia of Industrial Chemistry, VCH Verlagsgesellschaft, Weinheim 1998

[24] Peukert, W.; Vogel, L.: Breakage behaviour of different materials - construction of a mastercurve for the breakage probability, Powder Technology 129, 2003, 101-110

[25] Vogel, L.: Zur Bruchwahrscheinlichkeit prallbeanspruchter Partikeln, PhD-Thesis Technische Universität München, 2003 


\section{w'Author's short biography}

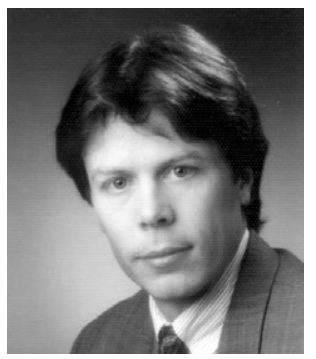

\section{Wolfgang Peukert}

Wolfgang Peukert studied chemical engineering at the University of Karlsruhe. After receiving his diploma, he worked towards his $\mathrm{PhD}$ in the group of Prof. Loeffler at the Institute of Mechanical Process Engineering in Karlsruhe. His PhDthesis is entitled "Combined collection of particles and gases in granular bed filters". In 1991, he joined Hosokawa Micron. He spent two years in Japan and then became the R\&D Director of Hosokawa MikroPul in Cologne. In 1998 he left Hosokawa to accept a chair for Particle Technology at the Technical University of Munich. Since March 2003, W. Peukert heads the Institute of Particle Technology at the University of Erlangen-Nuremberg. His research activities cover a broad range of subjects in the field of particle technology with special emphasis on product engineering and interface science and technology. W. Peukert serves as a referee for various organisations and journals and is active in several working groups. He is a member of the editorial board of Powder Technology, Particuology, and editor-in-chief of Particle \& Particle Systems Characterization. He has published more than 90 papers.

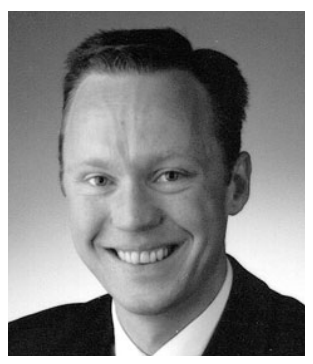

\section{Lutz Vogel}

Lutz Vogel studied chemical engineering at the University of Karlsruhe (Germany) from 1992 to 1996, majoring in particle technology and combustion technology. He graduated with a diploma in chemical engineering in March 1998 and then joined the group of Prof. Dr.-Ing. Wolfgang Peukert at the new Institute of Particle Technology of the Technische Universität München as a research associate and coworker. The characterisation and quantification of the grinding performance of different mills and the modelling of impact grinding processes are the main topics of his research work. He concluded his $\mathrm{PhD}$ thesis which is entitled "The Breakage Probability of Impacting Particles" in 2003. In May 2003, Lutz Vogel joined the Degussa AG at Hanau (Germany), where he continues to work in the field of particle technology. 